\title{
Outbreak of Zika virus pathogenesis and quest of its vaccine development: Where do we stand now?
}

\author{
Ameer Khusro $^{\mathrm{a}, *}$, Chirom Aarti $^{\mathrm{a}}$, Alberto Barbabosa-Pilego ${ }^{\mathrm{b}}$, Pedro Sánchez-Aparicio ${ }^{\mathrm{c}}$ \\ ${ }^{a}$ Research Department of Plant Biology and Biotechnology, Loyola College, Nungambakkam, Chennai, 600034, Tamil Nadu, India \\ b Facultad de Medicina Veterinaria y Zootecnia, Universidad Autónoma del Estado de México, Toluca, Mexico \\ ${ }^{c}$ Department of Pharmacology, Anesthesia and Analgesia, Faculty of Veterinary Medicine, Universidad Autónoma del Estado de México, Toluca, Mexico
}

\section{A R T I C L E I N F O}

\section{Keywords:}

Tropical infection

Vaccine

Viral infection

Zika virus

\begin{abstract}
A B S T R A C T
Zika virus (ZIKV) infection is a life-threatening tropical infection, mainly caused by mosquito bite. After a very long period of quietness, ZIKV infections have become a problematic issue again. Previously, the virus was limited to Africa and Asia only but later it emerged in Brazil, South America, and other parts of the world in 2015. In 2016, there are emerging new cases of sexually transmitted ZIKV infection as well. At present, there is no proper treatment and available pronounced vaccines for the treatment of ZIKV infection. The prime focal point of this review is not only to provide imperative epidemiological information on ZIKV infection in brief but also the current situation of vaccines testing on animal model as well as in clinical trial phases. Currently there is no human vaccine for this pestiferous viral infection. Therefore, prevention, proper management, and up-to-date recommendation are crucial to mitigate the possible risk of vector and non-vector transmission of ZIKV.
\end{abstract}

\section{Introduction}

Zika virus (ZIKV) infection is a mosquito-borne tropical infection that became the global public health concern in early 2016. Zika infection, caused by ZIKV (genus Flavivirus) is one of the most devastating threats of $21^{\text {st }}$ century. The virus was primarily known as zoonotic pathogen and can be transmitted by Aedes sp. mosquitoes. Zika virus was accidentally isolated from Rhesus monkeys (Macaca mulatta) in 1947 during jungle yellow fever research in the Zika forest, Uganda, Africa [1]. Zika virus is in the shape of enveloped and icosahedral measuring about $50 \mathrm{~nm}$ in size. The virus has a non-segmented, singlestranded, positive-sense ribonucleic acid (RNA) genome which is about $10.5-11.0 \mathrm{kbp}$ in size. The viral genome produces a polyprotein with more than 3000 amino acids and this polyprotein is then cleaved into three structural and seven non-structural proteins (Fig. 1) [1].

Zika virus infection in human was first reported in 1952 and it was documented that a 10-year-old Nigerian girl who presented with malaria-like fever with the absence of jaundice, had shown an elevation of specific serum antibodies to ZIKV, which previously happened to be exclusive for monkey species. This observation led to the detection of ZIKV in human across the globe. The global threat of ZIKV infection has allowed researchers to study extensively on its pathogenesis and possible serious complications. Recently, severe complications such as Guillain-Barre syndrome (GBS) and congenital microcephaly have come into the account following the explosive outbreaks in Brazil and Central America since early 2015 [2]. Fever, headache, red eyes (conjunctivitis), arthralgia, rash, and other neurological abnormalities, particularly microcephaly are the common symptoms of this deadly infection (Fig. 2). Despite the negligible total counts of infected people in the beginning, a recent devastating outbreak in Brazil in last 2-3 years caused huge populace to be suspected of this infection. In view of this, World Health Organization (WHO) declared this disease extremely threatening and alarming [2].

Zika can be transmitted via blood through Aedes sp. mosquitoes. But the transmission through blood is an infrequent process. There is also possibility of ZIKV transmission from mother to the baby during pregnancy (Fig. 3). Apart from this, recently, the sexually transmitted ZIKV infection has been reported worldwide. The pathogens are considered to pass into the semen or vaginal secretion and finally transmitting during sexual intercourse [3]. For ZIKV, it has already been proved that the virus can be seen in semen and can be infectious and lasts for a long time [4]. The virus might have high invasiveness due to its presence in transplacental transmission [5]. Additionally, male to male sexual transmission of the virus is also possible through anal sex [6].

\section{Epidemiology of ZIKV}

The mosquito-borne ZIKV transmission was firstly reported by

\footnotetext{
* Corresponding author.

E-mail address: armankhan0301@gmail.com (A. Khusro).
} 


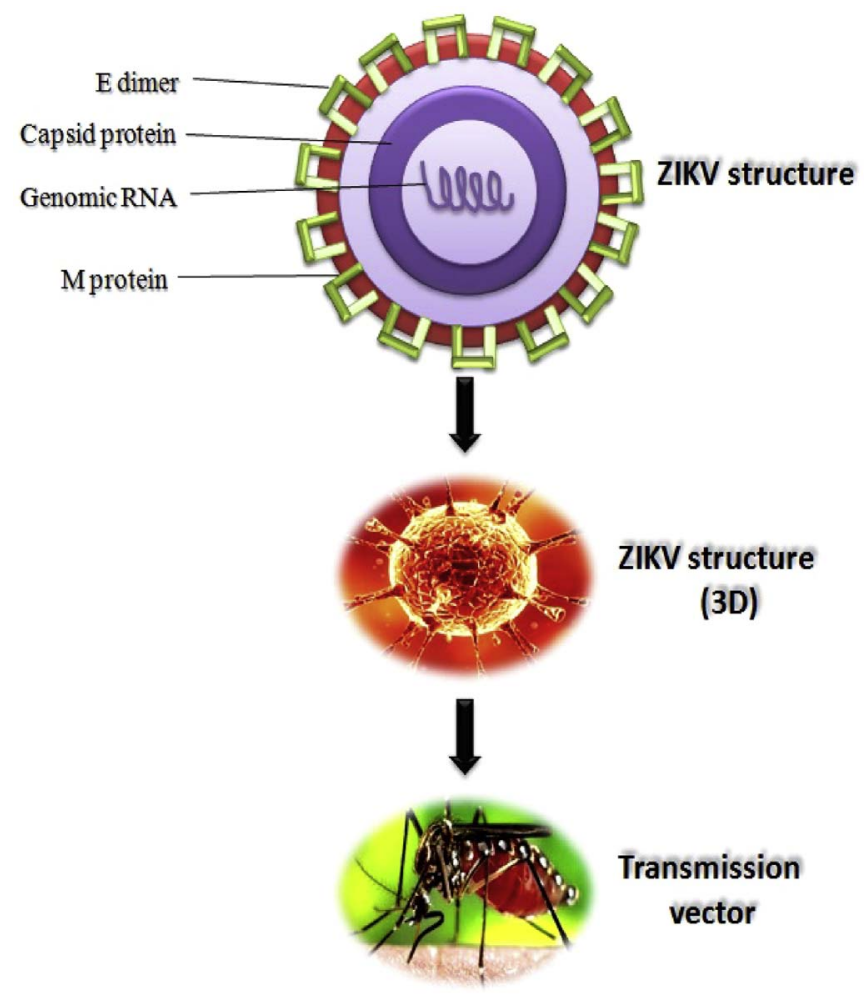

Fig. 1. Structure of ZIKV and its transmission agent.

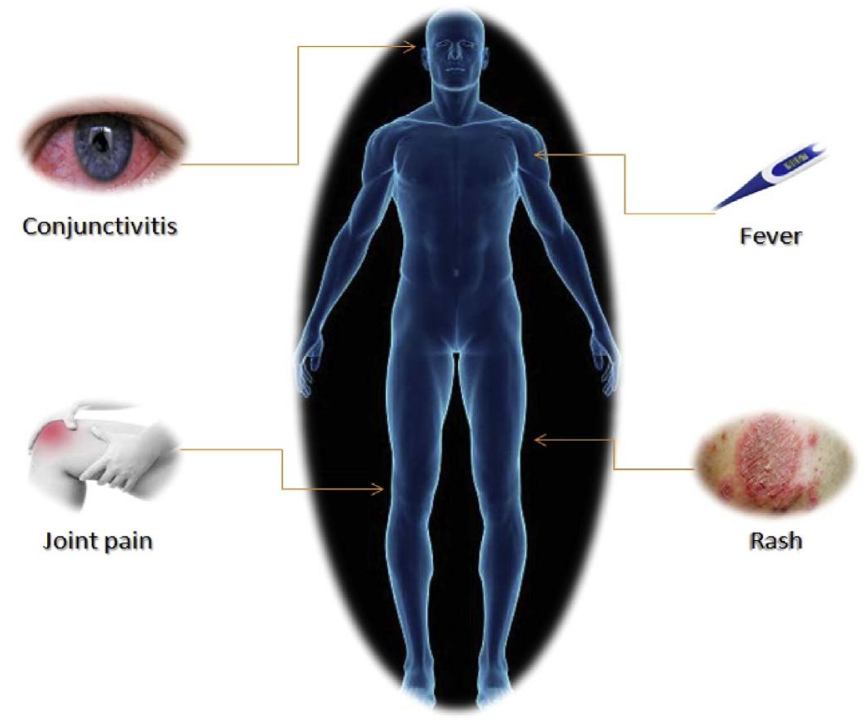

Fig. 2. Most common symptoms of Zika.

Brazil in May 2015 [7]. Various samples were collected from patients suffering from febrile rash illnesses, and thus confirmed the presence of ZIKV. However, the introduction of virus into Brazil was suggested to occur in 2013 as per phylogenetic and molecular clock analyses [8]. Colombia confirmed the presence of local mosquito-borne ZIKV transmission in October 2015. The transmission was subsequently reported from much of South America, Central America, the Caribbean, and parts of North America. Fig. 4 shows the prevalence of the ZIKV in various countries and territories worldwide.

Autochthonous mosquito-borne ZIKV transmission has been confirmed in 49 countries or territories in the Americas till date [9]. Interestingly, Bermuda, Canada, and Uruguay have not reported mosquito-borne transmission [10]. A total of 754460 suspected and laboratory-confirmed autochthonous cases of ZIKV infection had been reported to the Pan American Health Organization (PAHO) from countries and territories in the Americas from January 2015 to March 2017 [11]. Brazil (346475 cases; 46\%) is known for the highest suspected and confirmed cases, followed by Colombia (107206; 14\%), and Venezuela (62200; 8\%). Overall by region, South America accounted for $70 \%$ of reported cases, the Caribbean $21 \%$, Central America 9\%, and North America 1\%. The total cases of ZIKV infection increased in the Americas in February 2016. However, the incidence rate varied at variable times in different countries and sub-regions. In the South America and Central America region, incidence peaked in February 2016 and January 2016, respectively and subsequently declined [12].

Zika virus transmission will be interrupted in some areas, particularly in small island nations, but the infection is likely to become endemic in some countries of Americas [13]. An unusual increment in congenital microcephaly cases suspected to be associated with ZIKV infection during pregnancy were reported by the Brazilian Ministry of Health in late 2015. Twenty four countries and territories in the Americas had reported 2767 confirmed cases of microcephaly associated with ZIKV infection during pregnancy up to March 2017. Fourteen ZIKV infection cases (12 with travel to Pacific Island countries or territories and 2 with travel to Africa) were identified among US travellers from 2007 to 2014, based on testing performed at the Centres for Disease Control and Prevention (CDC) [14]. United States and the District of Columbia reported 4937 cases of laboratory-confirmed ZIKV disease among returning overseas travellers from January 2015 to April 2017. Overall, 3181 (64\%) reported cases were in female travellers. The most frequently reported travel destinations were countries and territories in the Caribbean (48\%), followed by Central America (16\%), North America (11\%), South America (4\%), Pacific Islands $(<1 \%)$, and Asia $(<1 \%)$. A total of 46 cases of ZIKV disease acquired through sexual transmission from returning travellers were also reported.

In Asia, occasional cases in residents and travellers and small outbreaks had been reported in the decades after recognition of ZIKV transmission in the region during the 1950s [15]. However, improved awareness and surveillance for ZIKV disease since the outbreak in the Americas have resulted in increased detection and reporting in the region. Retrospective testing of samples in Bangladesh, Cambodia, and Lao People's Democratic Republic identified previously unrecognized patients with ZIKV infection from last 5-10 years [16]. In November 2016, Vietnam became the second country in Southeast Asia to report a case of microcephaly linked with ZIKV [17]. The Ministry of Health reported the first local ZIKV in Singapore in August 2016, and several small clusters and sporadic cases have been reported into 2017 [18].

\section{Zika prevalence in India}

The Ministry of Health and Family Welfare-Government of India (MoHFW) reported three laboratory-confirmed cases of ZIKV in Bapunagar area, Ahmedabad District, Gujarat, India on May 2017.

The routine laboratory surveillance detected a laboratory-confirmed case of ZIKV through Reverse transcription polymerase chain reaction (RT-PCR) test at B.J. Medical College, Ahmedabad, Gujarat, India. The etiology of this case has been further confirmed through a positive RTPCR test and sequencing at the National Institute of Virology (NIV), Pune, India. Other two cases have then been identified through the Acute Febrile Illness (AFI) and the Antenatal clinic (ANC) surveillance.

Case I: A 34-year-old female, delivered a clinically well baby at B.J. Medical College in Ahmedabad on 9 November 2016. During this period, she developed a low grade fever after delivery. No history of fever during pregnancy and no history of travel for the past three months were reported. A sample from the patient was referred to the Viral Research and Diagnostic Laboratory (VRDL) at the B.J. Medical College for dengue testing and thereafter found to be positive for ZIKV. The sample was re-confirmed as ZIKV positive by RT-PCR and sequencing at NIV, Pune, India. 

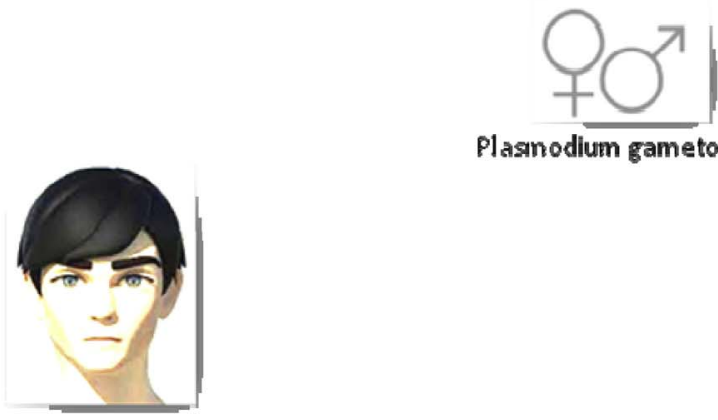

Second Infected person

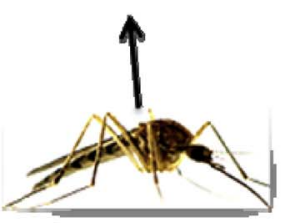

Aedes mosquif to (Second infex ted]
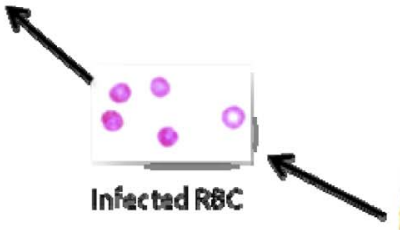

Lliver infettion

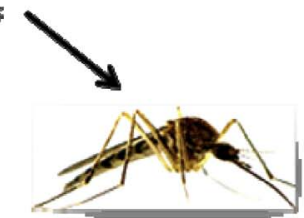

Aedas mosquit to (First infectedi

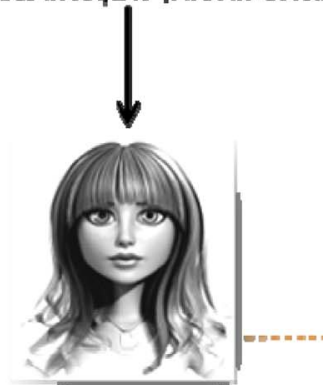

$\forall$

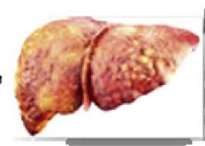

First Infectid porson

Fig. 3. Zika virus transmission cycle.

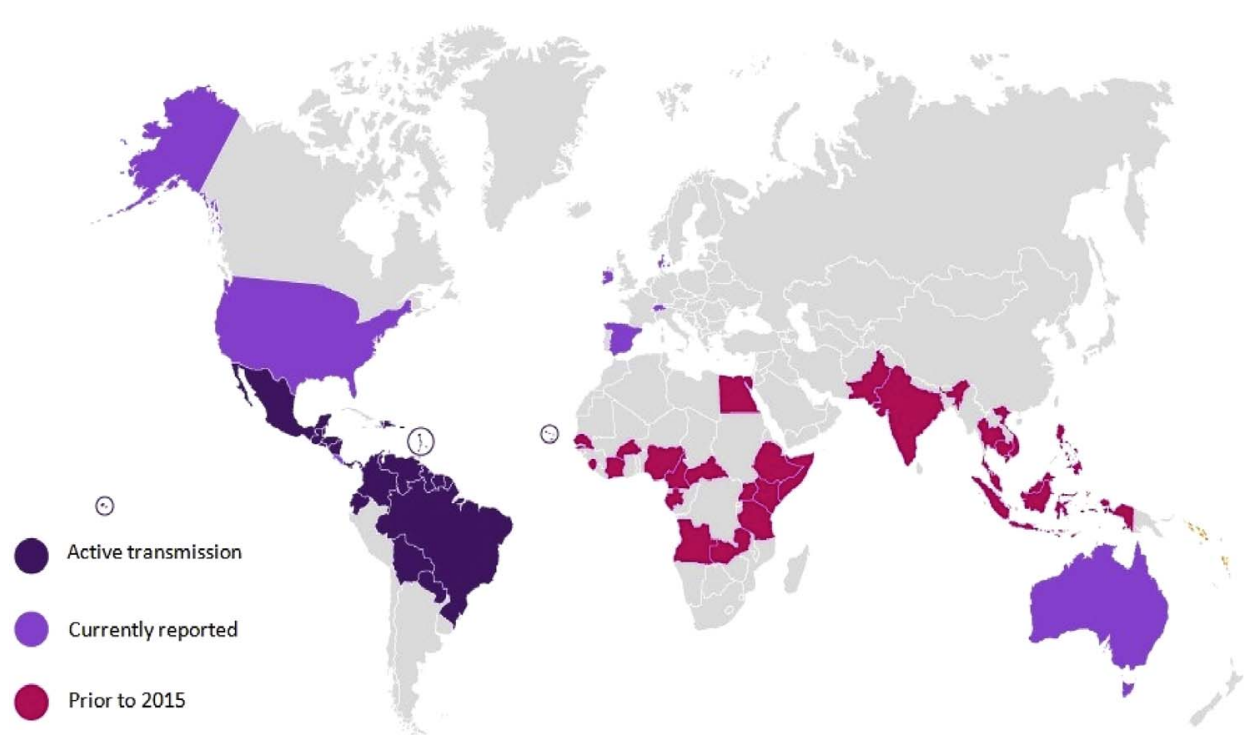

Fig. 4. Prevalence of the ZIKV in various countries and territories.

Case II: During the ANC surveillance between 6 and 12 January 2017, a total of 111 blood samples were collected at B.J. Medical College. One sample from a 22-year-old pregnant female in her $37^{\text {th }}$ week of pregnancy has been reported ZIKV positive.

Case III: During the AFI surveillance between 10 and 16 February 2017, a total of 93 blood samples were collected at B.J. Medical College, Ahmedabad, Gujarat, India. One sample from a 64-year-old male presenting with febrile illness up to 8 days was found to be ZIKV positive.

In addition to above mentioned cases, a new case of 27-year-old male from Krishnagiri district in Tamil Nadu has been reported positive for the ZIKV infection on July 1, 2017, thereby revealing the first case of Zika from Tamil Nadu. According to the preliminary investigation reports, no one from his family has travelled to any country where ZIKV is in circulation. Hence, the causative agent was suggested to be due to the local transmission. Among 200 suspected cases of the ZIKV tested at King Institute of Preventive Medicine and Research, Guindy, Chennai, this was the first case that was diagnosed positive for Zika.

In view of the ZIKV prevalence, Indian government is undertaking significant steps as mentioned below.

- Sharing of 'National Guidelines' and 'Action Plan' on this disease 
with the states to combat an outbreak of ZIKV infection and containment of prevalence in case of any outbreak.

- Setting up an 'Inter-Ministerial Task Force' under the Chairmanship of Secretary (Health and Family Welfare) together with Secretary (Bio-Technology), and Secretary (Department of Health Research).

- Displaying information for travellers on ZIKV infection by international airports and ports.

- Monitoring of vector control measures by the airport health officers along with airport organizations, National Centre for Disease Control (NCDC), and the National Vector Borne Disease Control Programme (NVBDCP).

- Tracking of AFI by the Integrated Disease Surveillance Programme (IDSP).

- Diagnosis of virus by NIV, Pune, India and NCDC, Delhi, India. Entomological laboratories are conducting ZIKV testing on mosquito samples.

- Monitoring of microcephaly by the Rashtriya Bal Swasthya Karyakram (RBSK).

- Finalizing the risk communication materials by the Central Health Education Bureau, in consultation with the United Nations Children's Fund (UNICEF).

\section{Zika virus prevalence in Mexico}

In epidemiological week (EW) 48 of 2015, the Mexico International Health Regulations (IHR) and National Focal Point (NFP) notified PAHO/WHO of the detection of two autochthonous Zika cases, vectorborne transmission, in the states of Nuevo León and Chiapas. The Instituto de Diagnóstico y Referencia Epidemiológicos (InDRE) performed the diagnostic tests. The first autochthonous Zika case was confirmed in a resident from Monterrey, the capital of Nuevo León State.

As of EW 34 of 2017, the Mexico Secretariat of Health has reported confirmed autochthonous Zika cases in 27 states. As of EW 34, the highest cumulative incidence rate of cases were reported in the order of Yutacán (61 cases per 100000 population), Colima (40 cases per 100000), Guerrero (25 cases per 100000), Veracruz (25 cases per 100000), and Quintana Roo (24 cases per 100000).

A significant increment in the total counts of confirmed Zika cases was observed until the peak in EW 39 of 2016. Further, an increased rate of Zika cases was observed from EW 20 to 26 of 2017. A total of 5065 confirmed cases of ZIKV in pregnant women were reported between 2015 and 2016. However, Mexico's Secretariat of Health has reported 602 confirmed cases of ZIKV in pregnant women between EW 1 and EW 34 of the same year (Fig. 5) [19].

The Mexico Secretariat of Health has also reported a total of 1131 cases of Guillain-Barre syndrome (GBS) in EW 30 of 2017, 11 being confirmed with ZIKV infection. The Mexico Secretariat of Health confirmed the first case of congenital syndrome associated with ZIKV infection on February 2017. Mexico has reported a total of 15 confirmed cases of congenital syndrome associated with ZIKV infection as of EW 30. As of November 2017 there have been 2742 confirmed cases of Zika across Mexico [20].

The most challenging part of the Zika is that there is no developed vaccine or any form of treatment to cure the patients, especially the pregnant women. In 2016, the investigation on the treatment of Zika has achieved a hallmark after the positive response of vaccine tested on animal models, and thus, enlightened a new hope for clinical trials studies in future.

\section{Zika virus vaccine: The beginning}

There are more than 40 vaccine candidates in preclinical development after the declaration of ZIKV a 'Public Health Emergency of International Concern' by WHO. Seven vaccine candidates are being evaluated in phase 1 clinical trials in the United States, Puerto Rico,
Austria, and India, and 1 candidate has entered phase $2 \mathrm{~b}$ evaluation in the United States and endemic sites in the Northern and Southern hemispheres (Table 1) [21].

In 2016, the Food and Drug Administration (FDA) approved a vaccine for ZIKV that will undergo clinical trial phases. The vaccine named GLS-5700 has already shown therapeutic role in mice and monkey. In fact, it is a DNA vaccine where DNA coded to produce the protein that surrounds the ZIKV is injected into the skin. GLS-5700 is a small circular piece of DNA, called a plasmid, which encodes the ZIKV premembrane and envelope (prM-Env) proteins. The site of the injection is zapped through electroporation that helps the DNA find its way into cells. The cells then trigger the mechanism of training the immune system to observe the ZIKV as a foreign invader that needs to be targeted by generating antibodies [22]. GLS-5700 is currently being evaluated in phase I clinical trials.

The National Institute of Allergy and Infectious Diseases (NIAID) is also designing DNA Zika vaccine based on its promising results on animals. The pre-clinical data has already shown good immunogenicity, and thus, the Phase I trial has been started.

In spite of tremendous effect of Zika vaccine in animals, there are still several years of testing and developmental work ahead before its commercialization. In fact, Phase I trials do not reveal the effectiveness of any product, but it can be a positive hallmark to determine whether a product is safe to administer to people and to estimate the promising dosage.

The pregnant women and women of child-bearing age would be the major target populace for a Zika vaccine, indicating a high safety bar. An effective DNA vaccine would likely satisfy safety concerns. Patients are supposed to receive 3 doses of either 1 or $2 \mathrm{mg}$ of GLS-5700, within a gap of 1 month. Primary outcomes include changes in laboratory safety measures and incidence of severe adverse events. Secondary outcomes are binding antibody titers to Zika Env, neutralizing antibody response against ZIKV, and T-cell response. The researchers expect to complete the phase I study successfully and then move into a phase II trial [23]. Researchers believe one dose of its vaccine should be adequate to protect, but the company will also test a two- and three-dose regimen [24]. The company has the potentiality to commercialize the Zika vaccine, though it currently does not have production facilities that can make the vaccine at commercial level.

Two DNA vaccine candidates (VRC5288 and VRC5283) are currently being tested by the Vaccine Research Center (VRC), NIAID, and National Institutes of Health (NIH). Based on the sequence of French Polynesian and early Brazilian ZIKV isolates, the VRC5288 expresses a codon-modified ZIKV/JEV chimeric prM-E. It was designed with the 98 amino acids of the $\mathrm{E}$ protein (comprising the transmembrane and stem domains) from JEV swapped with the corresponding regions from ZIKV E protein. This vaccine candidate is being evaluated in 80 subjects at 3 sites within the United States. The VRC5283 expresses the full ZIKV prM-E sequence in a 45-subject phase I clinical trial. Now, the VRC5283 has been moved to phase II clinical trial. Interestingly, both of these DNA vaccines were found to be immunogenic in mice and NHPs [25].

At present, 2 distinct mRNA vaccine approaches have been applied to ZIKV. The first is based on the use of modified nucleotides and codon optimization that increases stability and diminishes detection by intracellular innate immune sensors, thereby resulting in the higher magnitude and duration of vaccine antigen production [26,27]. Apart from this, intramuscular administration of 2 doses of mRNA-1325 vaccine was effective in immunocompetent mice treated with IFN- $\alpha / \beta$ antibody before ZIKV challenge and immunodeficient mice lacking the IFN- $\alpha / \beta$ and IFN- $\gamma$ receptors (AG129) [28]. Since, whole inactivated virus vaccines have been widely used for flaviviruses such as Yellow fever virus (YFV), Japanese encephalitis virus (JEV), and Tick-borne encephalitis virus (TBEV) [29], hence these vaccines are being pursued for ZIKV too. Bharat Biotechnologies, Hyderabad, India, began the development of a whole-inactivated ZIKV vaccine after the outbreak in French Polynesia in 2013. This vaccine candidate is now in phase I 


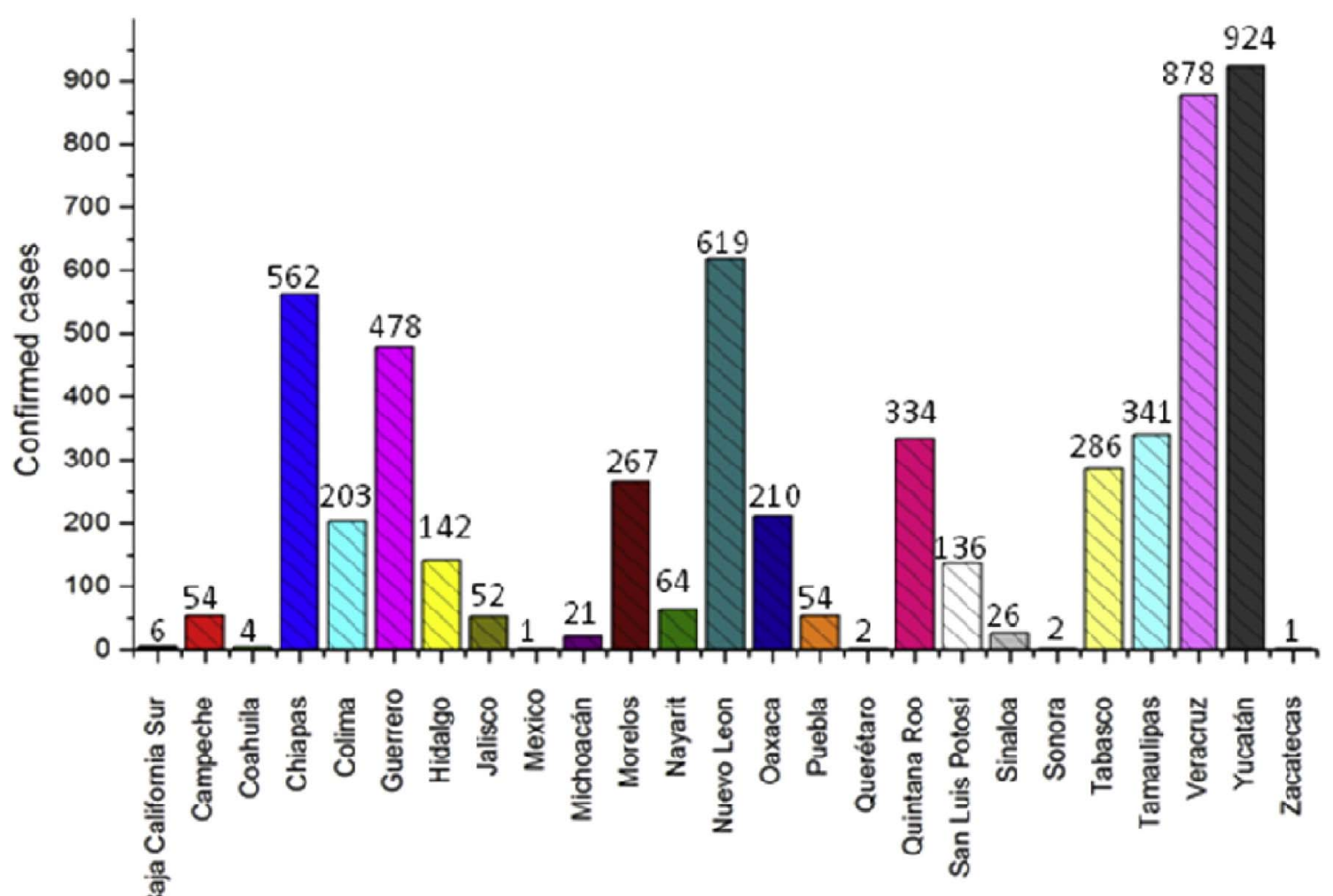

Federal states

Fig. 5. Confirmed cases of ZIKV infection in pregnant women between EW 1 and EW 34 [19].

Table 1

Zika virus vaccine in clinical development [21].

\begin{tabular}{|c|c|c|c|c|}
\hline Vaccine & Type & Vaccine name & Immunogen & Phase \\
\hline Nucleic acid & DNA & GLS-5700 & prME & I \\
\hline Nucleic acid & DNA & VRC5288 & prME & I \\
\hline Nucleic acid & DNA & VRC5283 & prME & I and II \\
\hline Nucleic acid & mRNA & mRNA-1325 & prME & I and II \\
\hline Vector based & Vector based & MV-Zika & prME & I \\
\hline $\begin{array}{l}\text { Whole } \\
\quad \text { inactivated }\end{array}$ & $\begin{array}{l}\text { Formalin } \\
\text { inactivated }\end{array}$ & ZPIV & Whole virus & I \\
\hline $\begin{array}{l}\text { Whole } \\
\text { inactivated }\end{array}$ & $\begin{array}{l}\text { Formalin } \\
\text { inactivated }\end{array}$ & $\begin{array}{l}\text { Purified } \\
\text { inactivated ZIKV }\end{array}$ & Whole virus & I \\
\hline
\end{tabular}

clinical trial [30]. Biomedical Advanced Research and Development Authority (BARDA) has supported Takeda Pharmaceutical and Sanofi Pasteur to develop whole-inactivated virus ZIKV vaccines.

In last few decades, a lot of work on DNA vaccines had been done for different infectious or non-infectious diseases, but so far none have reached to the market, except IMOJEV (for Japanese encephalitis, approved by regulatory authorities in Australia and Thailand).

\section{Other experimental vaccines in pipeline}

Larocca et al. [31] reported another DNA vaccine against ZIKV. On the other hand, a purified inactivated virus (PIV) vaccine had also been tested (Table 1). The researchers tested single doses of each vaccine in mice, which was then challenged with ZIKV from either northeast Brazil or Puerto Rico. The DNA vaccine described by Larocca et al. [31] is a plasmid encoding full-length Zika prM-Env proteins from the Brazil BeH815744 strain, as well as smaller portions of the Env protein. The researchers also tested the immunogenicity and protective property of a Zika PIV vaccine derived from the Puerto Rico PRVABC59 strain. Mice were vaccinated with $50 \mu \mathrm{g}$ DNA vaccine in saline without adjuvant intramuscularly or with $1 \mu \mathrm{g}$ PIV vaccine with $100 \mu \mathrm{g}$ alum adjuvant, intramuscularly or subcutaneously. The observations revealed that vaccine was able to protect mice completely against Zika infection, suggesting first report of complete ZIKV protection in an animal model. All of the vaccinated animals showed no detectable virus after challenge with ZIKV derived either from Brazil or Puerto Rico. Most importantly, the protection was achieved even after a single-shot immunization, suggesting the generalizability of these achievements. Zika PIV vaccine is being developed in collaboration with the NIAID, and that phase I trials have been started at the WRAIR and at NIAID partner sites.

\section{Human vaccine: We have to wait}

Results in mice are impressive and findings also suggest substantially that the development of a safe and efficacious ZIKV vaccine will likely be feasible. Most DNA vaccines are known to protect mice, but DNA vaccines so far do not reproduce their protective immunity in humans. Therefore, the outcomes here may lead developing the vaccine to phase I trial, but they will not likely have any direct influence on the development of a human vaccine. Researchers suggested that if the prM protein could be produced as a recombinant protein in lieu of a DNA vaccine, it might be an appropriate platform for developing human vaccine [31]. Another critical issue for developing an effective Zika vaccine is its safety during pregnancy and not inducing GBS. In a nutshell, the lack of successful translation of vaccine to humans will lead to the delay development of Zika vaccine in future for its commercialization.

\section{Strategic plan}

The "Zika Strategic Response Plan, Revised for July 2016-December 2017" mainly focuses on the prevention and management of medical complications caused by ZIKV [32]. It also discusses on integrated mosquito management, sexual as well as reproductive health 
counselling, and health care. The desideratum aim of this strategy is to support national governments and communities not only to prevent and manage the complications but also mitigate the socio-economic consequences of ZIKV infection. The ZIKV strategic plan works on following objectives-

i) Detection - This objective demonstrates the development and implementation of integrated surveillance systems for Zika in order to reveal up-to-date epidemiological and entomological information.

ii) Prevention - This objective focuses on the prevention of adverse health outcomes associated with ZIKV infection through integrated vector management, risk communication, and community engagement. In fact, controlling the spread of ZIKV requires diversified approach, concerning with vector control and protecting pregnant women as well as women of reproductive age from infection. This approach includes implementing integrated vector management (IVM), targeting all life stages of the Aedes mosquito: egg, larva/ pupa and the adult, reducing the risk of sexual transmission and other possible routes of transmission, and engaging and empowering communities, private sectors, etc. in mosquito control and prevention behaviours.

iii) Care and support - This objective focuses on the strengthen health and social systems at the national and community levels to provide appropriate services and support to individuals, families, and communities infected with ZIKV.

iv) Research - The main target of this objective is to generate data and evidence required for preventing, detecting, and controlling ZIKV infection. It aims to develop diagnostic products, vaccines, and other therapeutics for both ZIKV and its complications.

\section{Concluding remarks and future consideration}

The evidences showed that ZIKV infection is a global health concern and became a major issue for mankind. Since there is lack of effective treatment and human vaccine for Zika at present, proper screening, monitoring, and precaution need to be implemented worldwide. The emergence of ZIKV infection suggests that we should be more proactive focusing on basic aspects of viral structure, immunology, and pathogenesis relevant to the treatment in future. Despite the success of diverse antiviral agents in clinical trial phases, the development of new human vaccines to protect the global community from future outbreaks of ZIKV would be a challenging approach. Moreover, awareness and public health campaign are often required to get rid of this infection. Most importantly, the early onset of this infection needs to be avoided by proper management and multidisciplinary efforts.

\section{Conflicts of interest}

We declare that we have no conflict of interest.

\section{Abbreviations}

$\begin{array}{ll}\text { AFI } & \text { Acute Febrile Illness } \\ \text { ANC } & \text { Antenatal clinic }\end{array}$

BARDA Biomedical Advanced Research and Development Authority

$C D C \quad$ Centres for Disease Control and Prevention

EW Epidemiological week

FDA Food and Drug Administration

GBS Guillain-Barre syndrome

IHR Mexico International Health Regulations

InDRE Instituto de Diagnóstico y Referencia Epidemiológicos

IVM Integrated vector management

$J E V \quad$ Japanese encephalitis virus

MoHFW Ministry of Health and Family Welfare

NCDC National Centre for Disease Control

NFP National Focal Point
NIAID National Institute of Allergy and Infectious Diseases

$N I H \quad$ National Institutes of Health

NIV National Institute of Virology

NVBDCP National Vector Borne Disease Control Programme

$P A H O \quad$ Pan American Health Organization

PIV Purified inactivated virus

prM-Env Premembrane and Envelope

RBSK Rashtriya Bal Swasthya Karyakram

$R N A \quad$ Ribonucleic acid

$R T-P C R \quad$ Reverse transcription polymerase chain reaction

TBEV Tick-borne encephalitis virus

UNICEF United Nations Children's Fund

VRC Vaccine Research Centre

$V R D L \quad$ Viral Research and Diagnostic Laboratory

WHO World Health Organization

YFV Yellow fever virus

ZIKV Zika virus

\section{References}

[1] A.R. Salehuddin, H. Haslan, N. Mamikutty, N.H. Zaidun, M.F. Azmi, M.M. Senin, et al., Zika virus infection and its emerging trends in Southeast Asia, Asian Pac. J. Trop. Med 10 (2017) 211-219.

[2] A. Sabbir, M. Islam, M.M. Begum, S.K. Poddar, A. Ganguly, A review on Zika infection: from strain identification to Guillain-Barre syndrome complication, Asian Pac. J. Trop. Dis 6 (2016) 925-927.

[3] S. Wiwanitkit, V. Wiwanitkit, Sexually transmitted Zika virus infection: a new tropical disease, Asian Pac. J. Trop. Dis 6 (2016) 757-758.

[4] J.M. Turmel, P. Abgueguen, B. Hubert, Y.M. Vandamme, M. Maquart, H. Le GuillouGuillemette, et al., Late sexual transmission of Zika virus related to persistence in the semen, Lancet 387 (2016) 2501 https://doi.org/10.1016/S0140-6736(16) 30775-9.

[5] V. Wiwanitkit, Placenta, Zika virus infection and fetal brain abnormality, Am. J. Reprod. Immunol. 76 (2016) 97-98.

[6] D.T. Deckard, W.M. Chung, J.T. Brooks, J.C. Smith, S. Woldai, M. Hennessey, et al., Male-to-male sexual transmission of Zika virus-Texas, January 2016, Morb. Mortal. Wkly. Rep. 65 (2016) 372-374.

[7] Pan American Health Organization/World Health Organization, Zika Epidemiological Report Brazil. March 2017, PAHO/WHO, Washington, DC, 2017http://www2.paho.org/hq/index.php?option = com_docman\&task=doc_view \&gid $=35221 \& \&$ Itemid $=270$, Accessed date: 24 April 2017.

[8] G.S. Campos, A.C. Bandeira, S.I. Sardi, Zika virus outbreak, Bahia, Brazil, Emerg. Infect. Dis. 21 (2015) 1885-1886.

[9] World Health Organization, Situation Report: Zika Virus Microcephaly GuillainBarre Syndrome, (10 March 2017) http://apps.who.int/iris/bitstream/10665/ 254714/1/zikasitrep10Mar17-eng.pdf?ua =1 , Accessed date: 10 April 2017.

[10] J. Tognarelli, S. Ulloa, E. Villagra, J. Laqos, C. Aquayo, R. Fasce, et al., A report on the outbreak of Zika virus on Easter Island, South Pacific, 2014, Arch. Virol. 161 (2016) 665-668.

[11] Pan American Health Organization, Zika Suspected and Confirmed Cases Reported by Countries and Territories in the Americas: cumulative Cases, (2015-2017) Updated 9 March 2017 http://www2.paho.org/hq/index.php?option=com_ docman\&task $=$ doc_view\&itemid $=270 \&$ gid $=38588 \&$ lang $=$ en, Accessed date: 17 April 2017.

[12] Pan American Health Organization, Zika-epidemiological Update, (10 March 2017) http://www2.paho.org/hq/index.php?option $=$ com_docman\&task =doc_ view\&Itemid $=270 \&$ gid $=38610$ \&lang $=$ en , Accessed date: 17 April 2017 .

[13] World Health Organization, Zika Virus Country Classification Scheme: Interim Guidance. March 2017, World Health Organization, Geneva, Switzerland, 2017http://apps.who.int/iris/bitstream/10665/254619/1/WHO-ZIKV-SUR-17.1eng.pdf?ua $=1$, Accessed date: 30 March 2017.

[14] M.J. Hennessey, M. Fischer, A.J. Panella, et al., Zika virus disease in travellers returning to the United States, 2010-2014, Am. J. Trop. Med. Hyg. 95 (2016) 212-215.

[15] J.G. Olson, T.G. Ksiazek, Suhandiman, Triwibowo, Zika virus, a cause of fever in Central Java, Indonesia, Trans. R. Soc. Trop. Med. Hyg. 75 (1981) 389-393.

[16] World Health Organization, Situation Report: Zika Virus Microcephaly GuillainBarre Syndrome, (20 January 2017) http://apps.who.int/iris/bitstream/10665/ 253604/1/zikasitrep20Jan17-eng.pdf?ua =1 , Accessed date: 10 April 2017.

[17] World Health Organization, Situation Report: Zika Virus Microcephaly GuillainBarre Syndrome, (3 November 2016) http://apps.who.int/iris/bitstream/10665/ 250724/1/zikasitrep3Nov16-eng.pdf?ua =1 , Accessed date: 10 April 2017.

[18] Y.S. Leo, A. Chow, Zika virus has arrived in Singapore, Lancet Infect. Dis. 16 (2016) 1317-1319.

[19] Mexico Secretariat of Health, Zika Virus Disease Confirmed Cases, EW 34 of (2017) Available at: http://www.gob.mx/salud/acciones-y-programas/zika-informacionrelevante, Accessed date: 7 September 2017.

[20] Pan American Health Organization/World Health Organization, Zika Epidemiological Report Mexico. September 2017, PAHO/WHO, Washington, D.C., 2017. 
[21] K.M. Morabito, B.S. Graham, Zika virus vaccine development, J. Infect. Dis. 216 (2017) S957-S963.

[22] ClinicalTrials.gov, Study of GLS-5700 in Healthy Volunteers, (2016) [Online] Available from: https://clinicaltrials.gov/show/NCT02809443, Accessed date: 28 June 2016.

[23] Zika Vaccine Clinical Trials to Start in Humans this Month, (2016) [Online] Available from: http://www.medscape.com/viewarticle/865504, Accessed date: 28 June 2016.

[24] Experimental Zika Vaccine is Approved for Clinical Trials for First Time in US (2016) [Online] Available from: https://www.statnews.com/2016/06/20/zikavaccine-inovio/, Accessed date: 20 June 2016.

[25] K.A. Dowd, S.Y. Ko, K.M. Morabito, E.S. Yang, R.S. Pelc, C.R. DeMaso, et al., Rapid development of a DNA vaccine for Zika virus, Science 354 (2016) 237-240.

[26] D. Weissman, mRNA transcript therapy, Expert Rev. Vaccines 14 (2015) 265-281.

[27] U. Sahin, K. Kariko, O. Tureci, mRNA-based therapeutics-developing a new class of drugs, Nat. Rev. Drug Discov. 13 (2014) 759-780.

[28] J.M. Richner, S. Himansu, K.A. Dowd, S.L. Butler, V. Salazar, J.M. Fox, et al., Modified mRNA vaccines protect against Zika virus infection, Cell 168 (2017) 1114-1125.

[29] F.X. Heinz, K. Stiasny, Flaviviruses and flavivirus vaccines, Vaccine 30 (2012) 4301-4306.

[30] K. Sumathy, B. Kulkarni, R.K. Gondu, S.K. Ponnuru, N. Bonguram, R. Eligeti, et al., Protective efficacy of Zika vaccine in AG129 mouse model, Sci. Rep. 7 (2017) 46375 https://doi.10.1038/srep46375.

[31] R.A. Larocca, P. Abbink, J.P.S. Peron, P.M. de, A. Zanotto, M.J. Iampietro, A. Badamchi-Zadeh, et al., Vaccine protection against Zika virus from Brazil, Nature 536 (2016) 474-478.

[32] World Health Organization, Zika Strategic Response Plan: Revised for July 2016-December 2017, WHO Press, Geneva, 2016. 